\title{
DESIGN AND ANALYSIS OF LIFTING FIXTURES FOR CENTRE HOUSING UNIT
}

\section{K. BHAVANI \& DR. S. SURESH KUMAR}

Department of Mechanical Engineering, Saveetha School of Engineering,

Saveetha Institute of Medical and Technical Sciences, Chennai, Tamil Nadu, India

\section{ABSTRACT}

The main objective of this study is to design the lifting fixture for the centre housing component using Catia to avoid the usage of a belt for lifting purpose and also to analyse the minimum and maximum stress of the designed fixture for the given load using Ansys software. Fixture design is a vital role in handling the production side and it minimizes lifting problems during loading and unloading time. Belt usage has eliminated accidents and is easily operated by the operators. Thus the concluded result of two materials, is low alloy steel (SAE-AISI 4130) which has good tolerable nature in comparison the cast iron (ASTM GRADE 25) for all the tests by Catia V5-V6 and Ansys R18.0.

KEYWORDS: Fixtures, Centre Housing, Catia, FEM, Stress Analysis \& Design

Received: Jun 09, 2019; Accepted: Jun 29, 2019; Published: Sep 16, 2019; Paper Id.: IJMPERDOCT201936

\section{INTRODUCTION}

A fixture is a work-holding device which is used to clamp and hold the workpiece in a rigid state and also it won't allow the workpiece to change its position during machining. Cast iron is used for manufacturing the fixture which will exactly hold the work piece and will reduce the damage of workpiece while lifting. The workpiece is loaded and unloaded in the desired procedure with the help of the fixture designed which helps in minimum time consumption, less rejection and zero accidents.

The installation configuration starts with part displaying, machining and examination of different parts in the apparatus, together utilizing strong works for an investigation COSMOS programming bundle [1-3]. This paper is about demonstrating and examining with the help of sticks, for brake creepy crawly installation by FEA. This itemized investigation of Brake creepy crawly is completed by utilizing CATIA V5 demonstrating programming and it is assessed for the disappointment of help stick part by FEM utilizing ANSYS. This altered structure is adjusted in the creation of installation and is tried for its efficiency. From static investigation, most extreme cutting power and greatest cinching power are found. Most extreme static diversion and greatest pressure are additionally found [4-5]. Locating mistake and machining blunder were contemplated by precise strategy for blunder ID and figuring, in which utilizing limited component investigation (FEA) [6]. The discourse of different structure and examination techniques with regards to the quality of apparatus, diverse installation geometries are analysed and tentatively chosen. The capricious shaft apparatus will satisfy analyst production target and improve the proficiency; installation lessens task time and expands profitability, high calibre of activity [7-9]. A multi-target model was set up to build the appropriating consistency of mis-happening and to decrease the level of twisting. The distortion is broken down by advancing the limited component technique [10-14]. The assessment technique proposed in this paper will assess the clipping plan from a few angles as pursues: Area factor, Stability factor, area of clasping point factor. The mechanization of apparatus arranging assumes an essential job in improving the proficiency of installation structure and production 
[15]. Two similarity measurements are acquainted with the record of the worldwide and neighbourhood conformability. The plan factors are the number and position of installation component, apparatus component length, static coefficient, installation component tip span, and heading of the installation important solidness. Both power controlled and uprooting controlled apparatuses are considered. It was discovered that comparability and dependability can either expand nor decline with the situation of contacts relying upon their closeness to the line of activity of the outer annoyance. Cinching power and foremost firmness headings effect sly affect the security of power controlled and uprooting controlled apparatuses [16-18]. Installation is required in different enterprises as indicated by their application. Planner structure apparatus as indicated by measurement is needed by the industry to satisfy the creation of tar door. In conventional assembling procedure task on offbeat shaft is basic. The holding, a sample in legitimate states during an assembling task installation is very essential and significant. Since the pole is capricious prerequisite of assembling designed structure and legitimate apparatus for an unusual shaft. Installations decrease activity time and increments profitability and high calibre of activity are conceivable [19-21]. The present issue in the industry is confronting to the usage of pressure-driven equipment, which happens when grasping the work piece safely.

The primary target of the examination is to propose another structure of dances and apparatuses for pressure driven press to complete the grasping issue from existing structure. A few plan ideas were produced and recreated to break down utilizing ANSYS programming. The structure parameters, for example, most extreme mishappening, most extreme shear pressure, number of countenances, and most extreme holding power were introduced. In light of the recreation discussed, the establishment of dances and apparatuses plan for water-powered pressing machine was accomplished [22].

The aim and scope of this study is to predict the suitable strength of fixer materials without deformation using by Catia and Ansys. This study achieved the capable of lifting $110 \mathrm{Kg}$ centre housing component (Tractor Engine Housing parts), which is a lesser fixer weight in order of $5-7 \mathrm{Kg}$.

\section{MATERIALS AND METHOD}

\section{Materials Used}

Two materials have been used one is alloy steel (SAE-AISI 4130) and grey cast iron (ASTM GRADE 25).

\section{(SAE-AISI 4130)}

SAE-AISI 4130 is essentially used for shaping created products. 4130 is the assignment in both the SAE and AISI frameworks for this material. This is a medium carbon, low amalgam steel in ASTM A29 standard. It is an adaptable composite with great climatic erosion opposition and sensible quality up to around $315^{\circ} \mathrm{C}$.

\section{The Weight Percentage of SAE-AISI 4130}

$\mathrm{C}(0.28-0.33 \%), \mathrm{Cr}(0.8-1.1 \%), \mathrm{Mo}(0.15-0.25)$

\section{Grey Cast Iron (ASTM GRADE 25)}

Grey cast iron (ASMT GRADE 25) is sort of a solid metal that has a graphitic microstructure. It is named after the dark shade of the break it shapes, which is because of the nearness of graphite. It is the most well-known cast iron and the most generally utilized cast material dependent on weight. Evaluation 25 cast iron is dark as the given iron is manufactured under no temper or treatment condition. Evaluation 25 is the ASTM assignment for this material. It has the second most reduced quality contrasted with different variations of dark cast iron. 


\section{Composition of ASTM GRADE 25}

Carbon (3.25-3.5 \%), Chromium (0.050-0.45\%), Copper (0.15-0.40\%), Iron (91.9-94.2\%), Manganese (0.50-0.90 \%), Molybdenum (0.050-0.10\%), Nickel (0.050-0.20\%), Phosphorous $(<=0.12 \%)$, Silicon $(1.8-2.3 \%)$, Sulphur $(<=0.15 \%)$.

\section{Material Properties}

\begin{tabular}{|c|c|c|c|c|}
\hline \multicolumn{5}{|c|}{ Table 1: Material Property of Different Materials of the Fixture } \\
\hline Properties & $\begin{array}{c}\text { Density } \\
\left(\mathbf{g} / \mathbf{c m}^{\mathbf{3}}\right)\end{array}$ & Yield Strength (MPa) & Poisson's Ratio & Tensile Strength (MPa) \\
\hline SAE-AISI 4130 & 7.8 & 460 & 0.27 & 560 \\
\hline ASTM GRADE 25 & 7.5 & 110 & 0.29 & 190 \\
\hline
\end{tabular}

Note: Youngs modulus: 190GPa (SAE-AISI 4130) $190 * 10^{3} \mathrm{~N} / \mathrm{mm}^{2}$

Youngs modulus: 180GPa (ASTM GRADE 25) $180 * 10^{3} \mathrm{~N} / \mathrm{mm}^{2}$

Density $\left(\mathrm{IN} \mathrm{N} / \mathrm{m}^{3}\right): 76491.87 \mathrm{~N} / \mathrm{m}^{3}$ (SAE-AISI 4130)

Density (IN N/m ${ }^{3}$ ): $73549.87 \mathrm{~N} / \mathrm{m}^{3}$ (ASTM GRADE 25)

\section{Methods Used}

The fixture is designed to lift the centre housing component (figure 1). Study of fixture has been done, the materials are selected and assigned for the design of fixture. The fixture is designed using CATIA software and then the designed fixture is simulated and analysed for minimum and maximum stress using ANSYS software.

\section{Design of Fixture}

\section{Design Parameters}

- 2D model

- Dimensions extracted using Vernier calliper from the centre housing component

- Observation for fixture clamping

- $\quad$ Fixing of holder diameter

- $\quad$ CAD modelling of fixture using Catia

- Designed fixture
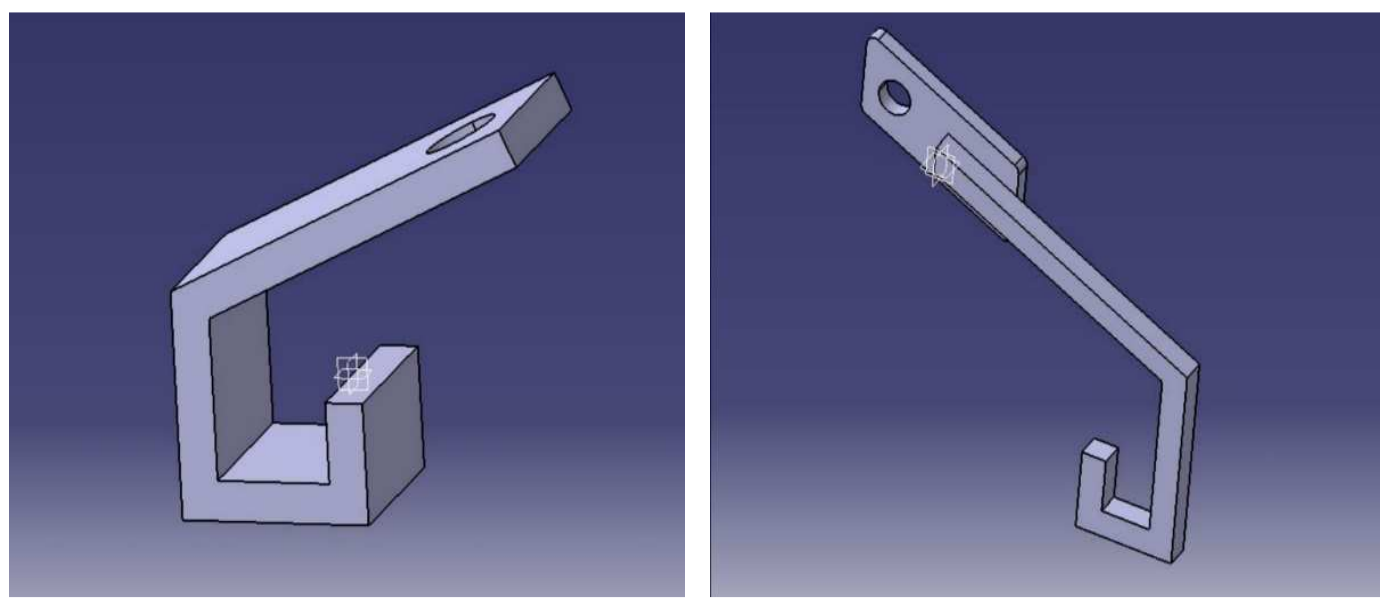

Figure 1: Fixture Designs for Centre Housing Component. 


\section{RESULTS AND CONCLUSIONS}

The results of the experimental study presented in this section. The primary purpose of this study was examining the stress analysis of the designed lifting fixture with two different materials using ansys and compare the result as to which material is suitable to manufacture the designed lifting fixture. The stress behaviour of the material is observed.

\section{Ansys Analysis}

\section{Von Mises Stress}

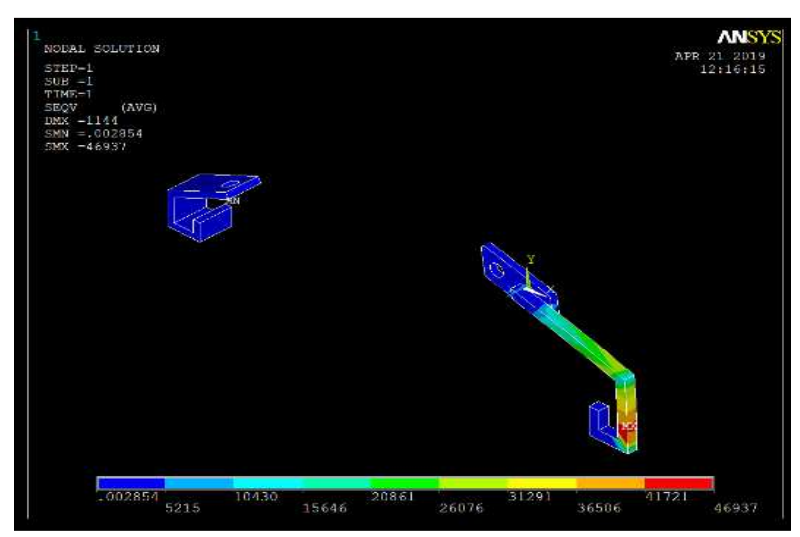

Figure 2: Von Mises Stress of SAE-AISI 4130.

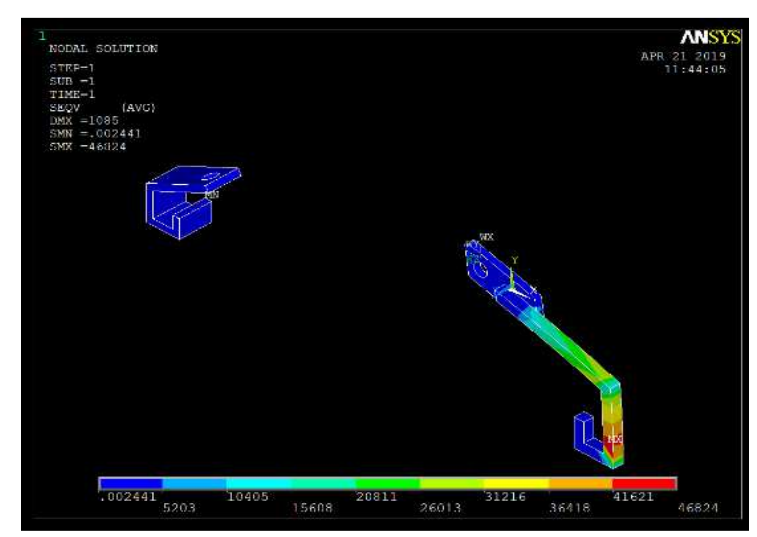

Figure 3: Von Mises Stress of ASTM Grade 25.

The von Mises yield basis (otherwise called the most extreme twisting vitality measure) recommends that yielding of a pliable material starts when the second deviatoric stress invariant achieves basic esteem. It is a piece of pliancy hypothesis that applies best to malleable materials, for example, a few metals. Before yield, the material reaction can be thought to be of a nonlinear versatile, viscoelastic, or straight flexible behaviour. In materials science and engineering, the von Mises yield standard can likewise be planned as far as the von Mises pressure or identical malleable pressure. This is a scalar estimation of stress that can be processed from the Cauchy stress tensor. For this situation, a material is said to begin yielding when the von Mises pressure achieves esteem known as yield quality. The von Mises pressure is utilized to foresee yielding of materials under complex stacking from the after effects of uniaxial ductile tests. The von Mises stress gave the two materials shown in figure 2 and 3. In figure 2 and 3 the colour coding denotes stress. The blue colour coding denotes minimum stress, red colour denotes maximum stress due to the lifting of the centre housing unit part and the intermediate colour denotes partial stress distribution on the fixer.

\section{Principal Stress}

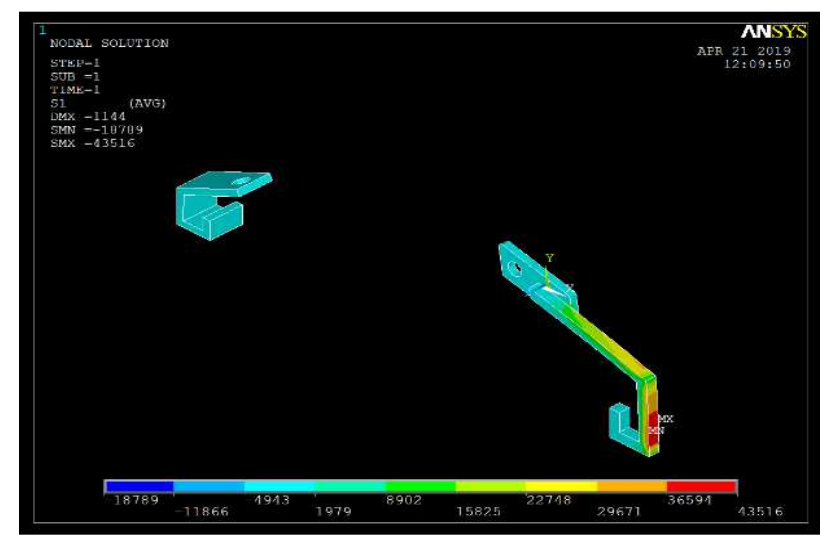

Figure 4: Principal Stress of SAE-AISI 4130.

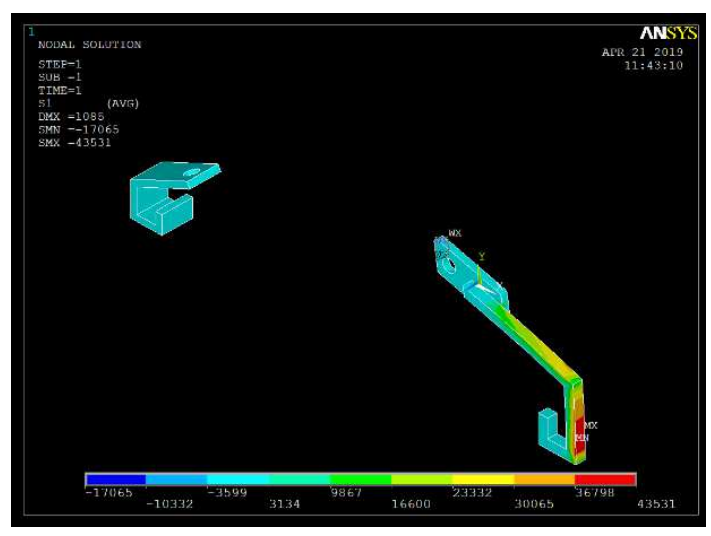

Figure 5: Principal Stress of ASTM Grade 25. 
The three anxieties ordinary to these main planes are called principal stresses. principal stress is characterized as the typical pressure determined at an edge when shear pressure is considered as zero. The ordinary pressure can be gotten for the most extreme and least qualities. The most extreme estimation of ordinary pressure is called as high principal stress and the least estimation of typical pressure is known as low principal stress (figure 4 and 5).

\section{Displacement Analysis}

A static analysis decides the displacement, stresses, strains, and powers in structures or parts brought about by loads that don't incite huge latency and damping impacts. It is shown in figure 6 and 7. Unfaltering stacking and reaction conditions are accepted; that is, the heaps and the structure's reaction is expected to fluctuate gradually for time. A static basic load can be performed utilizing the ANSYS.

The types of loading that can be connected in a static analysis include:

- Externally connected powers and weights

- Steady-state inertial powers, (for example, gravity or rotational speed)

- Imposed (nonzero) relocations

- $\quad$ Temperatures (for thermal strain)

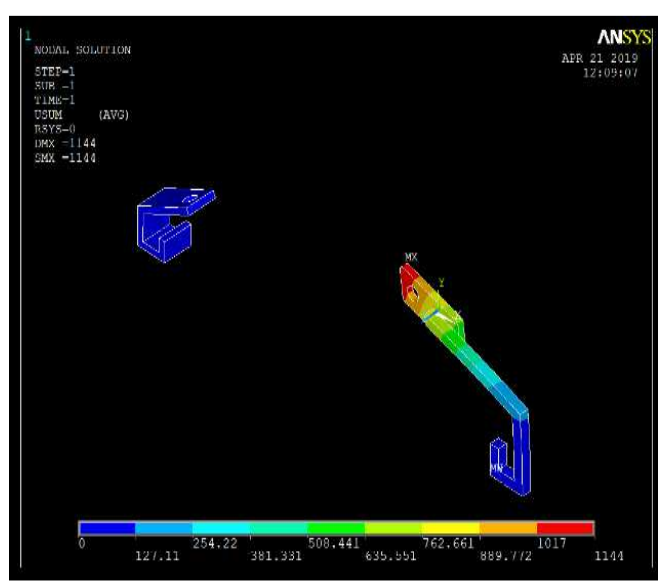

Figure 6: Displacement of Sae-Aisi 4130.

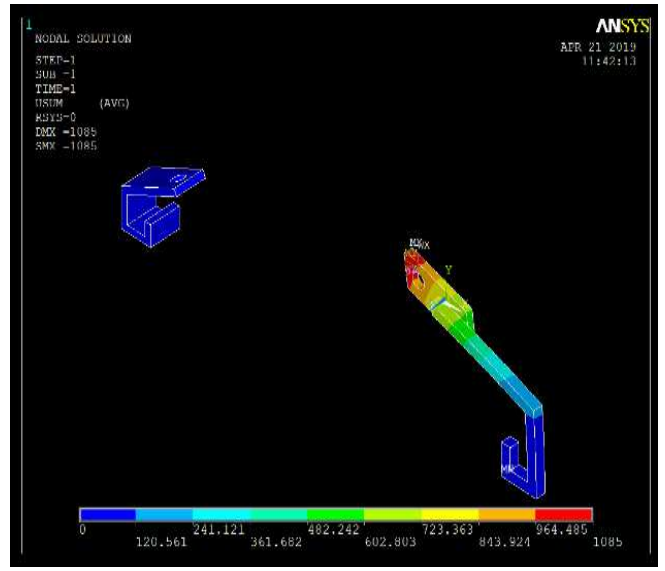

Figure 7: Displacement of Astm Grade 25.

\section{Analysis Result}

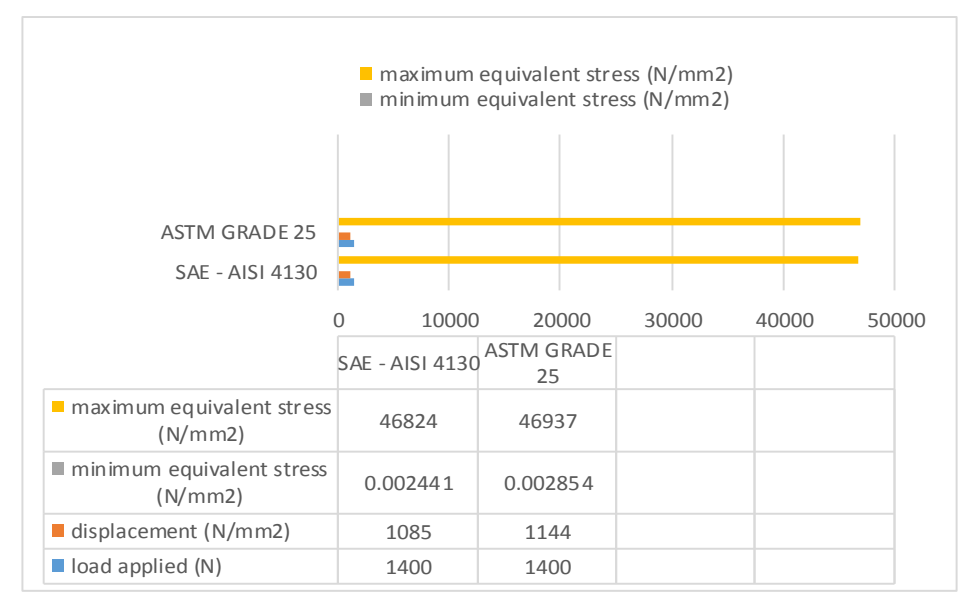

Figure 8: Material Stress Analysis Result. 
Table 2: Stress Analysis of Two Materials

\begin{tabular}{|c|c|c|c|c|}
\hline \multicolumn{1}{|c|}{ Materials } & $\begin{array}{c}\text { Load Applied } \\
(\mathbf{N})\end{array}$ & $\begin{array}{c}\text { Displacement } \\
\left(\mathbf{N} / \mathbf{m m}^{\mathbf{2}}\right)\end{array}$ & $\begin{array}{c}\text { Minimum Stress } \\
\left(\mathbf{N} / \mathbf{m m}^{\mathbf{2}}\right)\end{array}$ & $\begin{array}{c}\text { Maximum Stres } \\
\left(\mathbf{N} / \mathbf{m m}^{\mathbf{2}}\right)\end{array}$ \\
\hline SAE-AISI 4130 & 1400 & 1085 & 0.002441 & 46824 \\
\hline ASMT GRADE 25 & 1400 & 1144 & 0.002854 & 46937 \\
\hline
\end{tabular}

In this work, two materials were analysed and the stresses are listed in table 2 and figure 8

Table 2 shows the resultant values of displacement, minimum and maximum stress of testing materials during constant load applied. These values are found by Ansys. It is shown in table 2 and figure 8. This plot shows the material SAE-AISI 4130 with less deformation compared to the ASTM Grade 25 Material.

\section{CONCLUSIONS}

By Comparing stress distribution of two different materials ASTM GRADE 25 (Grey Cast Iron) material is having maximum deformation compared to SAE-AISI 4130, low alloy steel material. The material having minimum deformation will have good stability to lift the load. So, the material SAE-AISI 4130 will have more stability to lift the load without failure. From this study the results are concluded as follows:

- It is successfully optimized as the material of the Fixture.

- $\quad$ The study of structural stress of the fixture using ANSYS R18.0.

- The observation determined that the material which is having less deformation will have more stability for less failure of Fixture.

- It is concluded that the material SAE-AISI 4130 is less deformed and is suitable for fixture manufacturing of particular unit.

\section{REFERENCES}

1. C. Radha Madhavi, B. Ramu and K. Srinivasulu, Design of Machining Fixture for Turbine Rotor Balde, IJRET, P ISSN: 2321-7308.

2. Dr. Yadavalli Basavaraj and Pavan Kumar B K, Design and Analysis of Support Pin for Brake Spider Fixture by FEM Using Ansys Software, IOSR ISSN: 2278-1684 Volume 6, Issue (Mar-Apr.2013).

3. Y. Wang, X. Chen. N, Gindy, Surface Error Decomposition for Fixture Development, Int J Adv Manuf Technol DOI 10.1007/00170-005-0270, 2007.

4. Shrikant. V. Peshatwar, L. P Raut, Design and Development of Fixture for Eccentric Shaft: A Review, International Journal of Engineering Research and Applications (IJERA) ISSN: 2248-9622 Vol. 3, Issue 1, February 2013.

5. Weifang Chen, Lijun Ni \& Jianbin Xue, Deformation Control Through Fixture Layout Design and Clamping Force Optimization, Int J Adv Manuf Technol 38:860-867 DOI 10.1007/s00170-007-1153-2, 2008.

6. Nicholas Amaral · Joseph J. Rencis Yiming (Kevin) Rong Development of a Finite Element Analysis Tool for Fixture Design Integrity Verification and Optimization, Int J Adv Manuf Technol 25: 409-419, 2005.

7. Yan Zhuang, Ken Goldberg, Design Rules for Tolerance-Insensitive and Multipurpose Fixtures, ICAR 91Monterey, CA, July 7-9, 1997.

8. Jose F. Hurtado, Shreyes N. Melkote, "Effect of Fixture Design Variables on Fixture-Work Piece Conformability and Static Stability” 2001 IEEHASME International Conference on Advanced Intelligent Mechatronic Proceedings 8-12 July 2001 Cow Italy. 
9. Peshatwar S. V. and Raut L. P. (February 2013): Design and Development of Fixture for Eccentric Shaft: A Review, International Journal of Engineering Research and Applications (IJERA) ISSN: 2248-9622 www.ijera.com Vol. 3, Issue 1, January -pp.1591-1596.

10. Taufik, R.S.; Hirmanto, S.; Sivarao, Hambali, A. and Tajul A. A. (2012): Design of Jigs and Fixtures for Hydraulic Press Machine” Malikussaleh Industrial Engineering Journal Vo. 1 No. 1 (19-24) ISSN 2301-934X.

11. Raj, V. C. S., Rao, B. M., \& Prasad, V. Design of 30,000 dwt and 53,000 Dwt Bulk Carriers Both Conventional and Computer Aided Design Software.

12. Asada, H. and A.B. By. Kinematic Analysis of Work part Fixture for Flexible Assembly with Automatically Reconfigurable Fixtures, IEEE Journal of Robotics and Automation, Vol. 1 (2), pp. 86-94. 1985.

13. Cogun, C. The Importance of the Application Sequence of Clamping Forces. ASME Journal of Engineering for Industry, Vol. 114, pp. 539-543. 1992.

14. Daimon, M., Yoshida, T., Kojima, N., Yamamoto, H., Komatsu, and Hoshi, T. -Study For Designing Fixture Considering Dynamics Of Thin Walled Plate and Box-Like Work piece, \|l Annals of the CIRP, Vol. 34, No. 1, pp. 319-324, 1985.

15. Deb, K. - An Introduction to Genetic Algorithms, II Sadhana Journal, Vol. 24, pp. 293-315, 1999.

16. Deiab, I. M., Veldhuis, S. C. and Dumitrescu, M. -Dynamic Modeling of Face Milling Process Including The Effect of Fixture Dynamics, Transactions of NAMRI/SME, Vol. 30, pp. 461-468, 2002.

17. Fang, B., DeVor, R. E. and Kapoor, S. G.-An Elastodynamic Model of Frictional Contact and its Influence on the Dynamics of a Workpiece Fixture System, \| ASME J. Manuf. Sci. Eng., Vol. 123, pp. 481-489, 2001.

18. Hockenberger, M. J. and DeMeter, E. C. - The Effect of Machining Fixture Design Parameters on Workpiece Displacement, \| ASME, Manufacturing Review, Vol. 8, No. 1, pp. 22-32, 1995. International Journal of Engineering Research and General Science Volume 4, Issue 2, March-April, 2016 ISSN 2091-2730139 www.ijergs.org

19. Jayaram, K., Arun, C., \& Sakthivel, B. Design of Parallel Pipelined Feed Forward Architecture for Zero Frequency \& Minimum Computation (ZMC) Algorithm of Fft.

20. Haiyan Deng, - Analysis and Synthesis of Fixturing Dynamic Stability in Machining Accounting for Material Removal Effect, $\|$ Ph.D. thesis, Georgia Institute of Technology Atlanta, Georgia, 2006,

21. Hurtado, J. F. and Melkote, S. N.-A Model for the Prediction of Reaction Forces in A 3-2-1 Machining Fixture, Transactions of the North American Research Institution of SME, pp. 335-340, 1998.

22. Kang Y., Rong Y. and Yang J.A._Geometric and Kinetic Model Based Computer-Aided Fixture Design Verification, ASME Journal of Computing and Information Science in Engg., Vol.3, pp. 187-199, 2003.

23. Kulankara, K., Satyanarayana, S. and Melkote, S. N. -Iterative Fixture Layout and Clamping Force Optimization Using The Genetic Algorithm, Journal of Manufacturing Science and Engineering, Transactions of the ASME, Vol. 124, No. 1, pp.119-125, 2002.

24. Lai, X. M., Luo, L. J. and Lin, Z. Q.-Flexible Assembly Fixture Layout Modeling and Optimization Based on Genetic Algorithm, Chin. J. Mech. Eng., Vol. 1, pp. 89-92, 2004. 


\section{AUTHORS PROFILE}

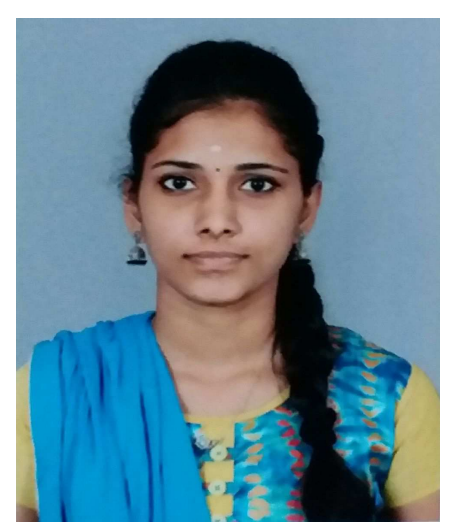

K. Bhavani B.E., Mechanical Engineering, Saveetha School of Engineering, Saveetha Institute of Medical and Techanical Sciences, Thandalam, Chennai.

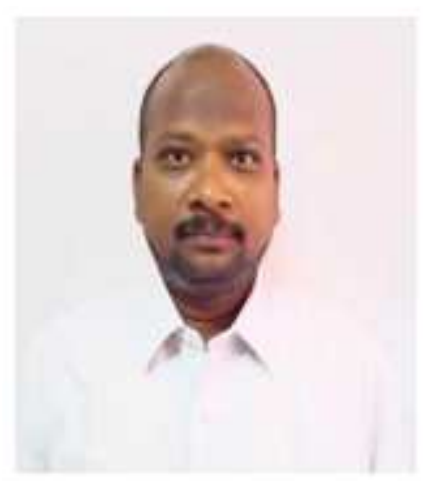

Dr. S. SURESH KUMAR, Assistant Professor, Senior Grade, Department of Mechanical Engineering, Saveetha Institute of Medical and Technical Sciences, (Saveetha University), Chennai, India. Member in American Society for Mechanical Engineers (ASME), USA (2008-2009). Member in American Society for Non-Destructive Testing (ASNT), USA (2007-2008). Member in American Petroleum Industry (API), USA, (2009 - 2010). 